\title{
Chronic stress moderates the impact of social exclusion on pain tolerance: an experimental investigation
}

This article was published in the following Dove Press journal:

Journal of Pain Research

17 May 2017

Number of times this article has been viewed

\author{
Karoline Pieritz' \\ Sarina J Schäfer ${ }^{2}$ \\ Jana Strahler ${ }^{3}$ \\ Winfried Rief' \\ Frank Euteneuer' \\ 'Division of Clinical Psychology \\ and Psychotherapy, Philipps \\ Universität, Marburg, ${ }^{2}$ Division \\ of Psychological Methods and \\ Evaluation, Fernuniversität, Hagen, \\ ${ }^{3}$ Division of Psychotherapy and \\ Systems Neuroscience, Justus-Liebig- \\ Universität, Giessen, Germany
}

Background: Experiences of social pain due to social exclusion may be processed in similar neural systems that process experiences of physical pain. The present study aimed to extend the findings on social exclusion and pain by examining the impact of social exclusion on an affective (ie, heat pain tolerance) and a sensory component of pain (ie, heat pain intensity). Whether a potential effect may be moderated by chronic life stress, social status, or social support was further examined.

Materials and methods: A community-based sample of 59 women was studied. Social exclusion and inclusion were experimentally manipulated by using a virtual ball-tossing game called Cyberball in which participants were randomly assigned to either being excluded or being included by two other virtual players. Heat pain tolerance and intensity were assessed before and after the game. Potential psychosocial moderators were assessed via a questionnaire. Results: The main finding of this study is that chronic stress moderates the impact of social exclusion on pain tolerance $(p<0.05)$. When chronic stress was high, socially excluded participants showed a lower heat pain tolerance than participants who were socially included. Contrary to the authors' hypothesis, pain sensitivity was increased in socially included participants compared with socially excluded participants after the game $(p<0.05)$.

Conclusion: Higher levels of chronic stress may enhance the vulnerability of affective pain processing to acute social exclusion.

Keywords: social pain, Cyberball, social inclusion, pain intensity, affective pain component, sensory pain component

\section{Introduction}

Previous findings indicate that the experiences of social pain (ie, the painful feelings following social exclusion) may rely on some of the same neurocognitive systems that process the experience of physical pain. ${ }^{1}$ The most obvious connection between social and physical pain is the use of physical pain words to describe negative social experiences across different languages and countries. ${ }^{2}$ From an evolutionary perspective, it has been suggested that both social exclusion and physical damage pose threats to individuals' survival. A system for processing physical pain is supposed to have developed early in the evolution and involves different components. The sensory-discriminative information about location, quality, and intensity of a noxious stimulus seems to be processed in the primary and secondary somatosensory cortices and the posterior insula. The affective-emotional component refers to the valence and the immediate affective response to a noxious stimulus. It has been linked to the dorsal anterior cingulate cortex (dACC) and the anterior insula (AI). Experiences of
Correspondence: Frank Euteneuer Division of Clinical Psychology and Psychotherapy, Philipps University of Marburg, Gutenbergstrasse 18, 35032 Marburg, Germany Tel +4964212823350 Fax +49 642I 2828904 Email frank.euteneuer@staff.uni-marburg. de 
social pain have been associated with similar neurocognitive systems and may thus increase the affective component of physical pain. ${ }^{3-5}$ As human civilization advanced, this system provided the foundation for a system processing social pain which punishes individuals who do not avoid social exclusion. ${ }^{2}$ Evidence for shared systems underlying social pain and physical pain comes from both animal and human research. For example, findings in non-human primates indicate that morphine, which is known for its analgesic effect, reduces separation-induced distress. ${ }^{6}$ Lesion and stimulation studies in animals suggest that the ACC, a region that has been linked to the affective component of pain, may also process distress associated with social separation and disconnection. ${ }^{7,8}$ Studies among healthy and clinical human samples have demonstrated that experiences of social pain (eg, poor social support, loneliness, and low social status) relate to a number of pain indicators..$^{9-13}$

In recent years, a growing number of studies in humans have examined the impact of social exclusion on psychological and physiological outcomes under laboratory conditions. ${ }^{14-17}$ The most frequently used method has been the Cyberball paradigm, a virtual ball-tossing game that has been demonstrated as a valid instrument to induce feelings of being socially included and excluded. ${ }^{18}$ Neuroimaging studies have shown that social exclusion (vs. inclusion) during Cyberball activates the dACC and the AI. ${ }^{19}$ In line with animal studies, ${ }^{7,8}$ these findings suggest that social exclusion may relate to the affective components of pain processing (ie, dACC, AI) rather than to the sensory components of pain processing such as the primary and secondary somatosensory cortices, as well as the posterior insula. ${ }^{1,20}$

Little research has been done on the impact of Cyberball social exclusion on experimental pain. Eisenberger et $\mathrm{al}^{21}$ demonstrated that in the social exclusion condition, baseline sensitivity to pain (ie, lower heat pain unpleasantness threshold) was associated with greater self-reported social distress in female undergraduate students. In addition, for socially excluded participants, greater reported levels of social distress were associated with greater reported levels of pain unpleasantness to the thermal stimuli delivered at the end of the Cyberball paradigm. There were no significant differences between excluded and included participants in thermal pain unpleasantness ratings after Cyberball. ${ }^{21} \mathrm{~A}$ second study has shown that undergraduates who were socially excluded during the Cyberball task exhibit increased pain sensitivity (ie, an overall measure based on pain tolerance and pain threshold measures). ${ }^{22}$ It is important to note that analgesic responses may also result from the experience of social threats, for example, if those threats are considered extremely strong and relate to the future. ${ }^{22-24}$

The present study aimed to extend the existing findings on social exclusion and pain by examining the impact of social exclusion on both an affective component of pain (ie, heat pain tolerance) and a sensory component of pain (ie, heat pain intensity). With respect to the inconsistent findings in existing studies, whether a potential effect may be moderated by major psychosocial determinants of health such as chronic life stress, social status, and social support is further examined. ${ }^{25-29}$ High levels of chronic stress, as well as low social status and social support, may enhance vulnerability to acute social exclusion and have been found to increase the impact of social threats and other stressors on psychobiological pathways which may be of relevance for pain processing (eg, ACC activation, autonomic imbalance, endocrine and inflammatory responses). ${ }^{30-41}$ While previous research has predominantly included female undergraduate students, ${ }^{21,22}$ the present study examined a community sample of women between 18 and 65 years to increase validity. ${ }^{42}$ It was hypothesized that 1 ) socially excluded participants experience more pain compared to socially included participants, 2) social exclusion may predominantly affect the affective component of pain (ie, pain tolerance), and 3 ) the effects of social exclusion on pain are stronger in participants who rank high levels on psychosocial risk factors compared with participants who rank low levels on psychosocial risk factors.

\section{Methods \\ Participants}

Participants were 59 healthy women (mean age $35 \pm 12$ years). They were recruited from the local community through advertisements, leaflets, and press releases in local newspapers. Only women were included since a number of recommendations suggest investigating female samples because of the greater prevalence of pain conditions in women and because of differences in pain processing between men and women. Furthermore, interaction effects of experimenter gender and participant gender should be avoided. ${ }^{43-45}$

Exclusion criteria were chronic illness and health problems which may affect pain processing (eg, cardiovascular disease, neuropathy, diabetes, and Raynaud's phenomenon), as well as mental health conditions which may affect pain and attention, respectively (eg, psychotic symptoms, alcohol, and/ or drug abuse). The study was approved by the ethics committee of the Philipps University of Marburg. Written informed consent was obtained from all participants for this study. 


\section{The Cyberball paradigm}

Participants played a virtual ball-tossing game called Cyberball, a commonly used and valid instrument to manipulate social exclusion in laboratory settings. ${ }^{18,46}$ Participants were told that they would be playing the game with two other players in different rooms and they would be connected to these players via the Internet. In reality, there were no other players. Participants played with a preset computer program that displayed cartoon images of the participant and the other players on a computer screen. The program was set for 30 throws per game and lasted between 1.5 and 2.5 minutes. Participants were randomly assigned to either 1) a social inclusion condition or 2) a social exclusion condition. Individuals in the inclusion condition played the interactive balltossing game for the entire time. Individuals in the exclusion condition were included for the first three throws of the game and then excluded by the two virtual players who stopped throwing the ball to them.

\section{Manipulation check}

As a psychometric manipulation check, participants' current mood states were measured before and after the Cyberball game. For this purpose, six 10-point Likert scales ranging from "strongly disagree" to "strongly agree" were used to assess how 1) embarrassed, 2) anxious, 3) angry, 4) depressed, 5) frustrated, or 6) happy participants felt.

As a physiological manipulation check, heart rate variability (HRV) and heart rate (HR) were obtained from cardiovascular measurements by using a Polar RS800 cardiac monitor (Polar Electro Ltd., Kempele, Finland).

In the case of successful experimental manipulation, one would expect that participants who experience social exclusion exhibit higher intensities of negative mood states, lower intensities of positive mood states, and lower HRV, compared with participants who experience social inclusion. ${ }^{47,48}$

\section{Pain tolerance and intensity}

Thermal stimuli from $32^{\circ} \mathrm{C}$ up to $52^{\circ} \mathrm{C}$ were employed to induce pain. Stimuli were delivered to the non-dominant forearm via a $3 \times 3 \mathrm{~cm}$ Peltier-based thermode (TSA II: Thermal Sensory Analyzer, Medoc Ltd, Ramat Yishai, Israel). Heat stimulation started at $32^{\circ} \mathrm{C}$ and rose with a slope of $0.5^{\circ} \mathrm{C} / \mathrm{s}$. Individuals were asked to tolerate the heat stimulus as long as possible and then stop it by pressing a button when they could no longer stand it. When stopped, the temperature dropped back to baseline with a decrease of $10^{\circ} \mathrm{C} / \mathrm{s}$. Participants were not given any information about the actual temperature of the stimuli during data collection. For further analyses, heat pain tolerance was determined by calculating the average of three measurements.

Heat pain intensity was assessed directly after each tolerance measurement by using a $10 \mathrm{~cm}$ long visual analog scale (VAS). The minimum was anchored with "no pain" and the maximum was anchored with "worst imaginable pain." For further analyses, an overall intensity mean value was computed by averaging the three intensity ratings.

\section{Psychosocial moderators Social support}

Social support was assessed by using the short version of the Social Support Questionnaire (F-SOZU). ${ }^{49}$ This 14-item self-report questionnaire combines several aspects of social support (ie, emotional support, practical support, and social integration) to a global social support score. Higher scores indicate a higher level of social support. This scale shows good psychometric-item properties and very acceptable reliability. ${ }^{49}$

\section{Subjective social status}

Subjective social status (SSS, ie, perceived social standing) was assessed with the German version ${ }^{50}$ of the MacArthur Scale of SSS. ${ }^{51}$ SSS, as assessed by this scale, refers to the individual's sense of their place on the social ladder. As in the English version, participants were asked to rate their place on two visual 10-rung social ladders: 1 ) in relation to those who are the best and worst off with respect to money, education, and respected jobs in Germany (SSS-G) and 2) in relation to those who have the highest and lowest standing in their social environment (SSS-SE). Lower scores indicate lower SSS. Of note, the English version of the second scale (SSSSE) asks people about their standing in relation to people in their community. Because the word "community" has no semantic equivalent in German, it was replaced by the term "social environment."

\section{Chronic stress}

The short version of the Trier Inventory for the Assessment of Chronic Stress (TICS) was used to measure chronic stress. ${ }^{52}$ The TICS consists of 12 items which capture the intensity of self-perceived stress during the last 3 months in five life domains: chronic worrying, work-related and social overload, excessive demands, and lack of social recognition. The TICS provides an overall score for chronic stress. Higher scores indicate a higher level of chronic stress. The assessment achieves good profile reliability. ${ }^{53}$ 


\section{Procedure}

All participants were tested individually. The examinations were conducted by a female student assistant. After giving written informed consent, participants completed sociodemographic and psychological questionnaires followed by baseline assessment of mood states, physiological measures, heat pain tolerance, and heat pain intensity. Subsequently, participants started playing the Cyberball game while physiological reactivity was recorded. When the game was finished, participants were asked to rate their mood states again followed by a second assessment of heat pain tolerance and heat pain intensity. Before completing the study with a thorough debriefing, individuals were asked whether they had already known about the Cyberball paradigm which none of the participants had.

\section{Data analysis}

\section{Analysis of physiological raw data}

For further analyses, a 2-minute resting interval before the beginning of the experiment and another 1.5-minute interval during the Cyberball game (the last 1.5 minutes before the game ends) were chosen. For quantification of HR and HRV, the most widely used time domain indices average HR (bpm), root mean square differences of successive heartbeat intervals (RMSSD), and in addition the percentage of successive intervals that differ by $>50 \mathrm{~ms}$ (pNN50) were obtained. ${ }^{54}$ Time domain variables were calculated because these are equivalent to frequency-domain variables as well as easier to perform. ${ }^{55}$ Both RMSSD and pNN50 reflect short-term alterations of HRV and are considered to be predominantly a response to changes in parasympathetic tone and mainly the respiratory component of HRV. Despite being highly correlated to power spectral measures of respiratory sinus arrhythmia (RSA), it has been suggested that RMSSD and pNN50 are not significantly affected by changes in breathing rate. ${ }^{56}$ All analyses were performed with Polar ProTrainer 5 (Polar Electro Ltd.) and Kubios HRV 2.0 software (Biomedical Signal Analysis Group, University of Kuopio, Kuopio, Finland).

\section{Statistical analysis}

Statistical analyses were carried out with SPSS Statistics version 21.0 for Windows (IBM Corporation, Armonk, NY, USA). Independent sample $t$-tests and chi-square tests were used to control for baseline differences between experimental groups. Analyses of covariance were used to examine the differences between participants in the exclusion condition and participants in the inclusion condition in heat pain tolerance and heat pain intensity, as well as in mood states, and physiological measures. Corresponding baseline values were included as covariates. PROCESS for $\mathrm{SPSS}^{57}$ was used to examine whether psychosocial factors moderate a potential impact of experimentally induced social exclusion on pain tolerance and pain intensity. Analyses for pain tolerance and pain intensity were adjusted for theoretical confounders such as age and oral contraceptives. ${ }^{58-60}$ All tests were two-tailed.

\section{Results}

\section{Baseline measures and manipulation check}

Baseline sample characteristics are shown in Table 1. There were no significant differences between participants in the social exclusion group and in the social inclusion group (all $p>0.1$ ) indicating successful randomization.

Table 2 shows the data after experimental manipulation. Compared to the participants in the inclusion condition,

Table I Baseline sample characteristics

\begin{tabular}{|c|c|c|}
\hline & $\begin{array}{l}\text { Inclusion } \\
(\mathbf{N}=\mathbf{3 0})\end{array}$ & $\begin{array}{l}\text { Exclusion } \\
(\mathbf{N}=\mathbf{2 9})\end{array}$ \\
\hline Age, years & $34.8(12.6)$ & $34.2(12.2)$ \\
\hline \multicolumn{3}{|c|}{ Winkler social class index, OSS } \\
\hline Educational level & $5.4(2.1)$ & $5.3(1.7)$ \\
\hline Profession & $3.7(1.6)$ & $3.6(1.4)$ \\
\hline Household net income & $1.9(1.4)$ & $1.6(I . I)$ \\
\hline Chronic stress & $1.6(0.7)$ & $1.6(0.6)$ \\
\hline Social support & $4.2(0.5)$ & $4.1(0.8)$ \\
\hline \multicolumn{3}{|c|}{ Subjective social status, MacArthur scale } \\
\hline National & $6.2(1.7)$ & $5.5(1.7)$ \\
\hline Social environment & $7.0(1.5)$ & $6.1(1.8)$ \\
\hline \multicolumn{3}{|l|}{ Mood states } \\
\hline Embarrassed & $0.3(0.8)$ & $0.03(0.2)$ \\
\hline Anxious & $0.4(0.6)$ & $0.5(1.5)$ \\
\hline Angry & $0.2(0.5)$ & $0.3(0.8)$ \\
\hline Depressed & $0.7(\mathrm{I} .4)$ & $1.0(1.9)$ \\
\hline Frustrated & $0.5(1.3)$ & $0.5(0.7)$ \\
\hline Happy & $4.6(2.8)$ & $4.2(2.7)$ \\
\hline Heart rate, bpm & $75.0(7.9)$ & $77.3(11.6)$ \\
\hline \multicolumn{3}{|l|}{ Heart rate variability, HRV } \\
\hline RMSSD & $37.6(14.7)$ & $39.8(22.5)$ \\
\hline pNN50, \% & $16.3(13.8)$ & 14.5 (II.9) \\
\hline Pain tolerance, ${ }^{\circ} \mathrm{C}$ & $46.3(2.3)$ & $46.1(2.2)$ \\
\hline Pain intensity, VAS & $6.3(1.7)$ & $5.9(2.3)$ \\
\hline
\end{tabular}

Notes: Values shown as mean (SD) unless otherwise noted. Mean scores equal: educational level=apprenticeship/vocational school; profession=middle grade of the civil service/qualified employee; household net income $=1000<1500 €$.

Abbreviations: bpm, beats per minute; HRV, heart rate variability; OSS, objective social status; pNN50, percentage of successive R-R (heartbeat) intervals that differ by $>50$ ms; RMSSD, root mean square differences of successive R-R intervals; SD, standard deviation; VAS, visual analog scale. 
Table 2 Measures after experimental manipulation

\begin{tabular}{|c|c|c|}
\hline & $\begin{array}{l}\text { Inclusion } \\
(\mathbf{N}=\mathbf{3 0})\end{array}$ & $\begin{array}{l}\text { Exclusion } \\
(\mathbf{N}=\mathbf{2 9})\end{array}$ \\
\hline \multicolumn{3}{|l|}{ Mood states } \\
\hline Embarrassed & $0.3(0.8)$ & $0.5(1.4)$ \\
\hline Anxious & $0.3(0.9)$ & $0.4(\mathrm{I} .2)$ \\
\hline Angry** & $0.1(0.5)$ & $1.5(2.2)$ \\
\hline Depressed & $0.6(1.3)$ & $1.2(2.3)$ \\
\hline Frustrated* & $0.7(1.8)$ & $1.9(2.2)$ \\
\hline Happy** & $4.9(2.9)$ & $3.7(2.6)$ \\
\hline Heart rate, bpm & $77.2(9.6)$ & $81.5(10.9)$ \\
\hline \multicolumn{3}{|c|}{ Heart rate variability, HRV } \\
\hline RMSSD & $42.6(21.6)$ & $34.2(16.8)$ \\
\hline $\mathrm{pNN} 50, \% *$ & $20.6(14.7)$ & $12.3(10.1)$ \\
\hline Pain tolerance, ${ }^{\circ} \mathrm{C}$ & $46.9(2.0)$ & $46.6(1.8)$ \\
\hline Pain intensity, VAS * & $6.9(1.8)$ & $6.1(2.3)$ \\
\hline \multicolumn{3}{|c|}{$\begin{array}{l}\text { Abbreviations: bpm, beats per minute; HRV, heart rate variability; pNN50, } \\
\text { percentage of successive R-R intervals that differ by }>50 \mathrm{~ms} \text {; RMSSD, root mean } \\
\text { square differences of successive R-R intervals; SD, standard deviation; VAS, visual } \\
\text { analog scale. }\end{array}$} \\
\hline
\end{tabular}

participants in the social exclusion group were more angry $[F(1,56)=10.318, p=0.002]$, more frustrated $[F(1,56)=5.756$, $p=0.020]$, and less happy $[F(1,56)=7.972, p=0.007]$. Moreover, pNN50 values were significantly lower in the social exclusion group compared with the social inclusion group $[F(1,47)=4.298, p=0.044]$.

\section{The effect of social exclusion on heat pain tolerance and intensity}

Although there was no general group difference in pain tolerance $[F(1,54)=0.17, p=0.68]$, moderation analyses indicated that chronic stress affects the impact of social exclusion on pain tolerance, $b=-1.10,95 \%$ CI $(-2.01,-0.19), t=-2.43$, $p<0.001$. When chronic stress was high, socially excluded participants showed a lower heat pain tolerance than participants who were socially included $(b=-0.86,95 \% \mathrm{CI}[-1.70$, $-0.02], t=-2.04, p=0.046)$. Figure 1 illustrates this moderation. At the mean value of chronic stress $(b=-0.11,95 \% \mathrm{CI}$ $[-0.70,0.49], t=-0.36)$ and when chronic stress was low $(b=0.65,95 \%$ CI $[-0.23,-1.53], t=1.48)$, there were nonsignificant effects $(p>0.1)$. The relationship between social exclusion and pain tolerance was not moderated by social support or SSS $(p>0.1)$. Results for pain intensity indicated that participants who experienced social exclusion reported significantly lower pain intensity ratings compared with the social inclusion group $[F(1,54)=4.46, p=0.04]$. There were no significant moderator effects for chronic stress, social support, or SSS $(p>0.1)$.

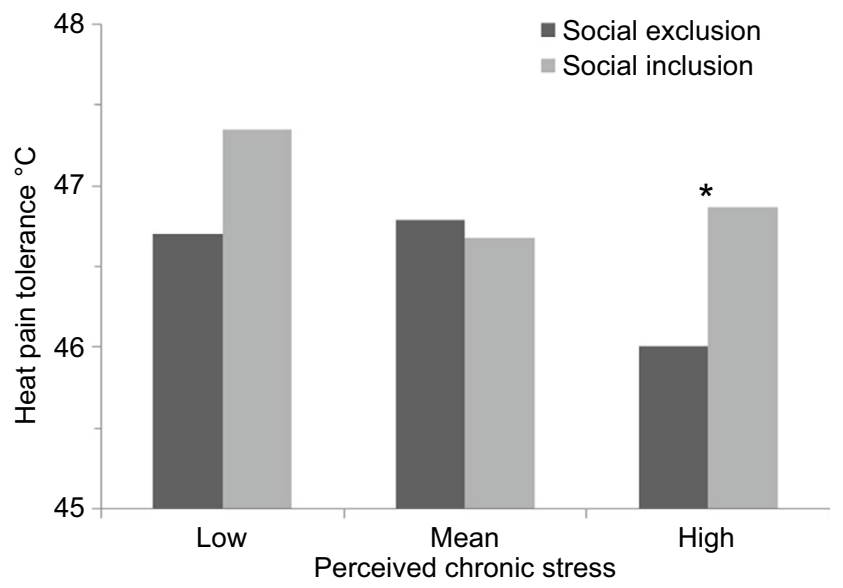

Figure I Chronic stress moderates the impact of social exclusion (vs. inclusion) on heat pain tolerance. When chronic stress is high (+I SD), socially excluded participants show a lower heat pain tolerance than participants who are socially included. At the mean value of chronic stress and when chronic stress is low (-I SD), there are no significant conditional effects $(p>0.1)$. ${ }^{*} p<0.05$.

Abbreviation: SD, standard deviation.

\section{Discussion}

The present study aimed to extend previous research on social exclusion and pain by examining the particular effect of social exclusion on both an affective component of pain (ie, heat pain tolerance) and a sensory component of pain (ie, heat pain intensity). Whether a potential effect may be moderated by major psychosocial determinants of health such as chronic life stress, social status, and social support was further examined. The main finding of this study is that chronic stress moderates the impact of social exclusion on pain tolerance. Consistent with the authors' hypotheses, socially excluded participants with high chronic stress had a lower heat pain tolerance than those who were socially included in the Cyberball game. Thus, it appears that higher levels of chronic stress may enhance the vulnerability of affective pain processing to acute social exclusion. This finding is consistent with a study reporting increased psychological and physiological reactivity for individuals with chronic life stress after being challenged with an acute psychological stressor. ${ }^{61}$ It is also in line with previous research demonstrating that chronic life stress and other social stressors (eg, social exclusion) may cause hyperalgesia and increase physical pain distress. . $^{2,22,62-66}$ The underlying mechanisms of this finding are not clear. With respect to the growing evidence of overlapping neural systems for social stressors and physical pain, chronic stress may lead to alterations within the body's pain pathways. ${ }^{66}$ For example, chronic stress has been suggested to cause increased activation in brain regions relevant for pain processing, such as the ACC, insula, and amygdala. ${ }^{66}$ Stress-induced changes in neurotransmission and neuroendocrine systems relevant 
for pain processing have also been found. ${ }^{66}$ Changes may include a desensitization of the endogenous opioid system, increased glutamate, and decreased gamma-aminobutyric acid (GABA) expression in the dorsal horn of the spinal cord or dysregulation of the hypothalamo-pituitary-adrenal (HPA) axis. Such alterations may impair the body's ability to suppress pain, resulting in lower pain tolerance. ${ }^{1,19,24,66-68}$

Contrary to the authors' hypotheses, an increase in the sensory pain component as defined by higher pain sensitivity ratings in socially included compared to socially excluded participants after the Cyberball game was found. This finding contrasts with a recent study by Canaipa et $\mathrm{al}^{62}$ who reported lower pain intensity ratings for socially included participants. Unlike us, however, they applied noxious electrical stimuli instead of thermal stimuli which might account for the different results. A possible explanation for this finding might be that participants perceived social inclusion as an indicator for a secure social environment. This may have increased their willingness to show vulnerability by stating higher pain intensity ratings after the game. This interpretation is supported by findings of higher pain reports of women in the presence of a same-sex friend ${ }^{69}$ and also by models of social reinforcement in chronic pain syndromes. ${ }^{70}$

The results of the present study seem to add to the growing evidence of overlapping neural systems for social stressors and affective pain processing. Although it is important to note that overlaps between these two systems do not necessarily describe specific mechanisms mediating between them. A strength of this study is that two different dimensions of pain (ie, pain tolerance as an affective component of pain, pain intensity as a sensory component of pain) were measured. Hence, it was possible to examine the specific impact of social exclusion versus social inclusion on both the components of pain processing. The findings of this study therefore extend previous research by suggesting that different components of pain may be differently affected by social exclusion. Another advantage of the current study is that pain stimuli were not delivered while participants were playing the Cyberball game, but right before and after the game. This procedure may avoid potentially distracting effects on pain perception. ${ }^{71-73}$ Since chronic stress is known to exacerbate existing pain, ${ }^{63,66}$ the findings of this study are also in accordance with recent recommendations for the clinical treatment of postoperative as well as chronic pain. Applying complementary methods to reduce social stressors and improve patients' mental well-being has been shown to be superior to an exclusively physical pain treatment. ${ }^{74-76}$

This study has some limitations. The sample size is relatively small. Furthermore, because only participants from the area of Marburg, Hesse (Germany), were included, the generalizability of the results of this study may be limited. The fact that subjects rated pain intensity after being exposed to different temperatures (the individual tolerance) might have had confounding effects on the results of this study for pain intensity. Future studies may use more distinct measures for affective and sensory pain components. They should replicate the authors' findings and also extend knowledge of the underlying mechanisms, for example by using neuroimaging techniques to examine the impact of social exclusion on both an affective and a sensory component of pain processing.

In conclusion, the findings of this study extend previous research on social exclusion and pain by suggesting that different components of pain may be differently affected by social exclusion. The main result is that socially excluded participants with high chronic stress had a lower pain tolerance than those who were socially included in the Cyberball game. Higher levels of chronic stress may enhance the vulnerability of affective pain processing to acute social exclusion.

\section{Acknowledgments}

The authors thank Johanna Trittien for assisting with the data collection.

\section{Disclosure}

The authors report no conflicts of interest in this work.

\section{References}

1. Eisenberger NI. Social pain and the brain: controversies, questions, and where to go from here. Annu Rev Psycho. 2015;66:601-629.

2. Macdonald G, Leary MR. Why does social exclusion hurt? The relationship between social and physical pain. Psychol Bull. 2005;131:202-223.

3. Fernandez E, Turk DC. Sensory and affective components of pain: separation and synthesis. Psycho. Bull. 1992;112:205-217.

4. Rainville P, Carrier B, Hofbauer RK, Bushnell MC, Duncan GH Dissociation of sensory and affective dimensions of pain using hypnotic modulation. Pain. 1999;82:159-171.

5. López JC. Sensory systems: the two sides of a painful story. Nat Rev Neurosci. 2001;2:536-536.

6. Kalin NH, Shelton SE. Effects of clonidine and propranolol on separation-induced distress in infant rhesus monkeys. Brain Res. 1988; 470:289-295.

7. Hadland KA, Rushworth MFS, Gaffan, D, Passingham RE. The effect of cingulate lesions on social behaviour and emotion. Neuropsychologia. 2003;41:919-931.

8. Robinson B. In: Altmann S, editor. Neurological aspects of evoked vocalizations. Social Communication Among Primates. Chicago: University Press; 1967:135-147.

9. Hoebel J, Kuntz B, Müters S, Lampert T. Subjective social status and health-related quality of life among adults in Germany. Results from the German General Social Survey (ALLBUS 2010). Gesundheitswesen. 2013;75:643-651.

10. Wolf LD, Davis MC. Loneliness, daily pain, and perceptions of interpersonal events in adults with fibromyalgia. Health Psychol. 2014;33:929-937.

11. Brown JL, Sheffield D, Leary MR, Robinson ME. Social support and experimental pain. Psychosom Med. 65(2):276-283. 
12. López-Martínez AE, Esteve-Zarazaga R, Ramírez-Maestre C. Perceived social support and coping responses are independent variables explaining pain adjustment among chronic pain patients. J Pain. 2008;9:373-379.

13. Dorner TE, Muckenhuber J, Stronegger WJ, Ràsky E, Gustorff B, Freidl W. The impact of socio-economic status on pain and the perception of disability due to pain. Eur J Pain. 2011;15:103-109.

14. Rotge J-Y, Lemogne C, Hinfray S, et al. A meta-analysis of the anterior cingulate contribution to social pain. Soc Cogn Affect Neurosci. 2015;10(1):19-27.

15. Sebastian C, Viding E, Williams KD, Blakemore S-J. Social brain development and the affective consequences of ostracism in adolescence. Brain Cogn. 2010;72:134-145.

16. Williams, K. D. Ostracism. Annu Rev Psychol. 2007;58:425-452.

17. Seidel EM, Silani G, Metzler H, et al. The impact of social exclusion vs. inclusion on subjective and hormonal reactions in females and males. Psychoneuroendocrinology. 2013;38:2925-2932.

18. Williams KD, Jarvis B. Cyberball: a program for use in research on interpersonal ostracism and acceptance. Behav Res Methods. 2006;38: $174-180$.

19. Eisenberger NI, Lieberman MD. Does rejection hurt? An fMRI. 2003;302(5643):290-292.

20. Treede RD, Kenshalo DR, Gracely RH, Jones AK. The cortical representation of pain. Pain. 1999;79:105-111.

21. Eisenberger N, Jarcho JM, Lieberman MD, Naliboff BD. An experimental study of shared sensitivity to physical pain and social rejection. Pain. 2006;126:132-138.

22. Bernstein MJ, Claypool HM. Social exclusion and pain sensitivity: why exclusion sometimes hurts and sometimes numbs. Pers Soc Psychol Bull. 2012;38:185-196.

23. DeWall CN, Baumeister RF. Alone but feeling no pain: effects of social exclusion on physical pain tolerance and pain threshold, affective forecasting, and interpersonal empathy. J Pers Soc Psychol., 2006;91: $1-15$.

24. Eisenberger NI. The pain of social disconnection: examining the shared neural underpinnings of physical and social pain. Nat Rev Neurosci. 2012;13:421-434.

25. Uchino BN, Cacioppo JT, Kiecolt-Glaser JK. The relationship between social support and physiological processes: a review with emphasis on underlying mechanisms and implications for health. Psychol Bull. 1996;119:488-531.

26. Euteneuer F. Subjective social status and health. Curr Opin Psychiatry. 2014;27:337-343.

27. Cohen S, Wills TA. Stress, social support, and the buffering hypothesis. Psychol Bull. 1985;98:310-357.

28. McGonagle KA, Kessler RC. Chronic stress, acute stress, and depressive symptoms. Am J Community Psychol. 1990;18:681-706.

29. Wilkins R, Marmot M. The Social Determinants of Health: The Solid Facts. 2nd ed. World Health Organization Europe; 2003. Available from: apps.who.int/iris/bitstream/10665/108082/1/e59555.pdf. Accessed March 27, 2013.

30. Lennartsson A-K, Theorell T, Kushnir MM, Bergquist J, Jonsdottir IH. Perceived stress at work is associated with attenuated DHEA-S response during acute psychosocial stress. Psychoneuroendocrinology. 2013;38:1650-1657.

31. Hellhammer J, Vogt D, Franz N, Freitas U, Rutenberg D. A soy-based phosphatidylserine/phosphatidic acid complex (PAS) normalizes the stress reactivity of hypothalamus-pituitary-adrenal-axis in chronically stressed male subjects: a randomized, placebo-controlled study. Lipids Health Dis. 2014;13:121.

32. Christenfeld N, Gerin W. Social support and cardiovascular reactivity. Biomed Pharmacother. 2000;54:251-257.

33. Ditzen B, Schmidt S, Strauss B, Nater UM, Ehlert U, Heinrichs M. Adult attachment and social support interact to reduce psychological but not cortisol responses to stress. J Psychosom Res. 2008;64:479-486.

34. Eisenberger NI, Taylor SE, Gable SL, Hilmert CJ, Lieberman MD. Neural pathways link social support to attenuated neuroendocrine stress responses. Neuroimage. 2007;35:1601-1612.
35. Gramer M, Reitbauer C. The influence of social support on cardiovascular responses during stressor anticipation and active coping. Biol Psychol. 2010;85:268-274.

36. Kirsch JA, Lehman BJ. Comparing visible and invisible social support: non-evaluative support buffers cardiovascular responses to stress. Stress Health. 2015;31(5):351-364.

37. Roberts MH, Klatzkin RR, Mechlin B. Social support attenuates physiological stress responses and experimental pain sensitivity to cold pressor pain. Ann Behav Med. 2015;49(4):557-569.

38. Uchino BN. Social support and health: a review of physiological processes potentially underlying links to disease outcomes. J Behav Med. 2006;29:377-387.

39. Gonzalez MZ, Beckes L, Chango J, Allen JP, Coan JA. Adolescent neighborhood quality predicts adult dACC response to social exclusion. Soc Cogn Affect Neurosci. 2015;10(7):921-928.

40. Derry HM, Fagundes CP, Andridge R, Glaser R, Malarkey WB, Kiecolt-Glaser JK. Lower subjective social status exaggerates interleukin-6 responses to a laboratory stressor. Psychoneuroendocrinology. 2013;38:2676-2685.

41. Low CA, Salomon K, Matthews KA. Chronic life stress, cardiovascular reactivity, and subclinical cardiovascular disease in adolescents. Psychosom Med. 2009;71:927-931.

42. Wintre MG, North C, Sugar LA. Psychologists' response to criticisms about research based on undergraduate participants: a developmental perspective. Can Psychol. 2001;42:216-225.

43. Greenspan JD, Craft RM, LeResche L, et al. Studying sex and gender differences in pain and analgesia: a consensus report. Pain. 2007;132(Suppl):S26-S45.

44. Ellermeier W, Westphal W. Gender differences in pain ratings and pupil reactions to painful pressure stimuli. Pain. 1995;61:435-439.

45. Kállai I, Barke A, Voss U. The effects of experimenter characteristics on pain reports in women and men. Pain. 2004;112:142-147.

46. Williams KD. Published Articles Using Cyberball; 2012. Available from: http://www1.psych.purdue.edu/ willia55/Announce/Cyberball_Articles.htm. Accessed March 27, 2013.

47. Boesch M, Sefidan S, Ehlert U, et al. Mood and autonomic responses to repeated exposure to the Trier Social Stress Test for Groups (TSST-G). Psychoneuroendocrinology. 2014;43:41-51.

48. Allen AP, Kennedy PJ, Cryan JF, Dinan TG, Clarke G. Biological and psychological markers of stress in humans: focus on the Trier Social Stress Test. Neurosci Biobehav Rev. 2014;38:94-124.

49. Fydrich T, Sommer G, Tydecks S, Brähler E. Fragebogen zur sozialen Unterstützung (F-SozU): Normierung der Kurzform (K-14). [Social Support Questionnaire (F-SozU): Standardization of short form (K-14)] $Z$ Med Psychol; 2009;18:43-48. German.

50. Euteneuer F, Süssenbach P, Schäfer S, RiefW. Subjective Social Status MacArthur Scales for the Assessment of Subjective Social Status in the Social Environment (SSS-U) and in Germany (SSS-D) [Subjektiver sozialer Status - MacArthur Skalen zur Erfassung des wahrgenommenen sozialen Status im soziale. Verhaltenstherapie. 2015;25:229-232.

51. Adler NE, Epel ES, Castellazzo G, Ickovics JR. Relationship of subjective and objective social status with psychological and physiological functioning: preliminary data in healthy white women. Health Psychol. 2000;19:586-592.

52. Schulz P, Schlotz W, Becker P. Trierer Inventar zum chronischen Stress (TICS). [Trier Inventory for Chronic Stress (TICS)]. Göttingen: Hogrefe; 2004. German

53. Schulz P, Schlotz W. Trierer Inventar zur Erfassung von chronischem Sre (TICS): Skalenkonstruktion, teststatistische Überprüfung und Validierung der Skala Arbeitsüberlastung. [The Trier Inventory for the Assessment of Chronic Stress (TICS). Scale construction, statis]. Diagnostica. 1999;45:8-19. German.

54. Rajendra Acharya U, Paul Joseph K, Kannathal N, Lim CM, Suri JS. Heart rate variability: a review. Med Biol Eng Comput. 2006;44:1031-1051.

55. Task Force of the European Society of Cardiology and the North American \& Society of Pacing and Electrophysiology. Heart rate variability: standards of measurement, physiological interpretation, and clinical use. Eur Heart J. 1996;17:354-381. 
56. Penttilä J, Helminen A, Jartti T, et al. Time domain, geometrical and frequency domain analysis of cardiac vagal outflow: effects of various respiratory patterns. Clin Physiol Oxford Engl. 2001;21:365-376.

57. Hayes AF. PROCESS: A Versatile Computational Tool for Observed Variable Mediation, Moderation, and Conditional Process Modeling [White paper]; 2012. Available from: http://www.afhayes.com/public/ process2012.pdf. Accessed March 27, 2013.

58. Gibson SJ, Farrell M. A review of age differences in the neurophysiology of nociception and the perceptual experience of pain. Clin J Pain. 2004;20:227-239.

59. Goubert D, Danneels L, Cagnie B, et al. Effect of pain induction or pain reduction on conditioned pain modulation in adults: a systematic review. Pain Pract. 2015;15(8):765-777.

60. Rezaii T, Ernberg M. Influence of oral contraceptives on endogenous pain control in healthy women. Exp Brain Res. 2010;203:329-338.

61. Pike JL, Smith TL, Hauger RL, et al. Chronic life stress alters sympathetic, neuroendocrine, and immune responsivity to an acute psychological stressor in humans. Psychosom Med. 1997;59:447-457.

62. Canaipa R, Treister R, Lang M, Moreira JM, Caldas AC. Feeling hurt: pain sensitivity is correlated with and modulated by social distress. Clin J Pain. 2016;32(1):14-19.

63. Hannibal K, Bishop M. (290) The effects of chronic stress on cortical responsiveness to suprathreshold heat stimuli: an fMRI study of painfree volunteers. J Pain. 2015;16:S48.

64. Rivat C, Becker C, Blugeot A, et al. Chronic stress induces transient spinal neuroinflammation, triggering sensory hypersensitivity and long-lasting anxiety-induced hyperalgesia. Pain. 2010;150:358-368.

65. Imbe H, Iwai-Liao Y, Senba E. Stress-induced hyperalgesia: animal models and putative mechanisms. Front Biosci. 2006;11:2179-2192.
66. Jennings EM, Okine BN, Roche M, Finn DP. Stress-induced hyperalgesia. Prog Neurobiol. 2014;121:1-18.

67. Eisenberger NI. The neural bases of social pain: evidence for shared representations with physical pain. Psychosom Med. 2012;74:126-135.

68. Hannibal KE, Bishop MD. Chronic stress, cortisol dysfunction, and pain: a psychoneuroendocrine rationale for stress management in pain rehabilitation. Phys Ther. 2014;94:1816-1825.

69. McClelland LE, McCubbin JA. Social influence and pain response in women and men. J Behav Med. 2008;31:413-420.

70. Fillingim RB, Doleys DM, Edwards RR, Lowery D. Spousal responses are differentially associated with clinical variables in women and men with chronic pain. Clin J Pain. 2003;19:217-224.

71. Johnson MH. How does distraction work in the management of pain? Curr Pain Headache Rep. 2005;9:90-95.

72. Sprenger C, Eippert F, Finsterbusch J, Bingel U, Rose M, Büchel C. Attention modulates spinal cord responses to pain. Curr Biol. 2012;22:1019-1022.

73. Kohl A, Rief W, Glombiewski JA. Acceptance, cognitive restructuring, and distraction as coping strategies for acute pain. J Pain. 2013;14: 305-315.

74. Ritchie C, Kenardy J, Smeets R, Sterling M. StressModEx - Physiotherapist-led stress inoculation training integrated with exercise for acute whiplash injury: study protocol for a randomised controlled trial. J Physiother: 2016;62(2):59.

75. Kamper SJ, Apeldoorn AT, Chiarotto A, et al. Multidisciplinary biopsychosocial rehabilitation for chronic low back pain: Cochrane systematic review and meta-analysis. BMJ. 2015;350:h444.

76. Bigeleisen PE, Goehner N. Novel approaches in pain management in cardiac surgery. Curr Opin Anaesthesiol. 2015;28:89-94.
Journal of Pain Research

\section{Publish your work in this journal}

The Journal of Pain Research is an international, peer reviewed, open access, online journal that welcomes laboratory and clinical findings in the fields of pain research and the prevention and management of pain. Original research, reviews, symposium reports, hypothesis formation and commentaries are all considered for publication.

\section{Dovepress}

The manuscript management system is completely online and includes a very quick and fair peer-review system, which is all easy to use. Visit http://www.dovepress.com/testimonials.php to read real quotes from published authors. 